\title{
Fast-track surgery improves postoperative clinical recovery and cellular and humoral immunity after esophagectomy for esophageal cancer
}

Lantao Chen ${ }^{1+}$, Lixin Sun ${ }^{2+}$, Yaoguo Lang ${ }^{1}$, Jun Wu ${ }^{1,3}$, Lei Yao ${ }^{1}$, Jinfeng Ning ${ }^{1}$, Jinfeng Zhang ${ }^{1}$ and Shidong Xu ${ }^{1 *}$

\begin{abstract}
Background: Our aim was to investigate the influence of FTS on human cellular and humoral immunity using a randomized controlled clinical study in esophageal cancer patients.

Methods: Between October 2013 and December 2014, 276 patients with esophageal cancer in our department were enrolled in the study. The patients were randomized into two groups: FTS pathway group and conventional pathway group. The postoperative hospital stay, hospitalization expenditure, and postoperative complications were recorded. The markers of inflammatory and immune function were measured before operation as well as on the 1st, 3rd, and 7th postoperative days (POD), including serum level of interleukin-6 (IL-6), C-reactive protein (CRP), serum globulin, immunoglobulin $\mathrm{G}(\mathrm{lgG})$, immunoglobulin $\mathrm{M}(\mathrm{IgM})$, immunoglobulin A (IgA) and lymphocyte subpopulations (CD3 lymphocytes, CD4 lymphocytes, CD8 lymphocytes and the CD4/CD8 ratio) in the patients between the two groups.

Results: In all, 260 patients completed the study: 128 in the FTS group and 132 in the conventional group. We found implementation of FTS pathway decreases postoperative length of stay and hospital charges $(P<0.05)$. In addition, inflammatory reactions, based on IL-6 and CRP levels, were less intense following FTS pathway compared to conventional pathway on POD1 and POD3 $(P<0.05)$. On POD1 and POD3, the levels of IgG, IgA, CD3 lymphocytes, CD4 lymphocytes and the CD4/CD8 ratio in FTS group were significantly higher than those in control group (All $P<0.05$ ). However, there were no differences in the level of IgM and CD8 lymphocytes between the two groups.
\end{abstract}

Conclusions: FTS improves postoperative clinical recovery and effectively inhibited release of inflammatory factors via the immune system after esophagectomy for esophageal cancer.

Trial registration: ChiCTR-TRC-13003562, the date of registration: August 29, 2013.

Keywords: Esophageal cancer, Fast-track surgery, Cellular immunity, Humoral immunity

\footnotetext{
* Correspondence: xwkxsd@outlook.com

${ }^{\dagger}$ Equal contributors

'Department of Thoracic Surgery, Harbin Medical University Cancer Hospital,

Harbin, Heilongjiang Province, China

Full list of author information is available at the end of the article
} 


\section{Background}

Since its introduction in the 1990s, the concept of fasttrack surgery (FTS) has gained widespread acceptance and is now considered as a standard of care. FTS also referred to as enhanced recovery after surgery (ERAS) have been implemented in order to enhance recovery, reduce morbidity and mortality rates, and shorten hospital stay after major surgery. The aim of this novel approach to perioperative patient care is to decrease the perioperative stress response to the surgical trauma and thereby leading to a decrease in complication rates in surgery. These promising clinical results lead to the question of whether the concept of FTS also results in better-preserved immune function in the postoperative course. Some researchers believe that FTS also has positive effects on the human immune system, which may result in quicker recovery of postoperative immune function [1]. Nevertheless, few clinical studies results have reported the impact of FTS on human immunity. Therefore, based on the hypothesis and present evidence of the benefits of FTS, we prospectively studied 276 patients underwent esophagectomy for esophageal cancer who either received FTS pathway or conventional pathway in the perioperative period. In addition to clinical outcome parameters, we analysed the effects of FTS on proinflammatory cytokine IL-6 and CRP levels as well as immunoglobulin and lymphocyte subgroups before surgery and on days 1, 3 and 5 after surgery.

\section{Methods}

\section{Patients and procedures}

This study was conducted in the Department of Thoracic Surgery at Harbin Medical University Cancer Hospital from October 2013 to December 2014.
Inclusion criteria included: age $\geq 18$ and $\leq 75$ years, American Society of Anesthesiologists (ASA) grade I/ II, body mass index (BMI) $18.5-27.5 \mathrm{~kg} / \mathrm{m}^{2}$, resectable esophageal cancer (page 36, NCCN Guidelines version 1.2013). However, we found in our previous clinical study involving patients with confounding factors that such factors might have a great impact on the results, such as immunological parameters for both controlled and observational groups. Therefore, some patients needed to be excluded from our study. The exclusion criteria of the study were as follows: patients with known immunological dysfunction (advanced liver disease (decompensated cirrhosis, portal hypertension or hepatocellular carcinoma), HIV infection, hepatitis $\mathrm{C}$ virus infection), pulmonary insufficiency (An acute or chronic condition marked by impaired pulmonary function, characterized by elevated carbon dioxide or decreased oxygen, or both), unresectable esophageal cancer (page 36, NCCN Guidelines version 1.2013), ASA III-IV, Karnofsky index less than 60 , BMI less than $18.5 \mathrm{~kg} / \mathrm{m}^{2}$, and age of 65-75 years with hypertension, diabetes, or vascular disease. Two hundred and seventy-six patients who were clinically diagnosed as having esophageal cancer were assigned to two groups comprising 138 patients each: FTS group and conventional group. Enrolled patients were randomly assigned to two groups using computer-generated random numbers. For approximately equal allocation to the two treatments, we took odd and even numbers to indicate treatments A (FTS group) and B (conventional group), respectively. The patients were admitted to different peri-operative care wards based on the computer-generated random numbers when they were

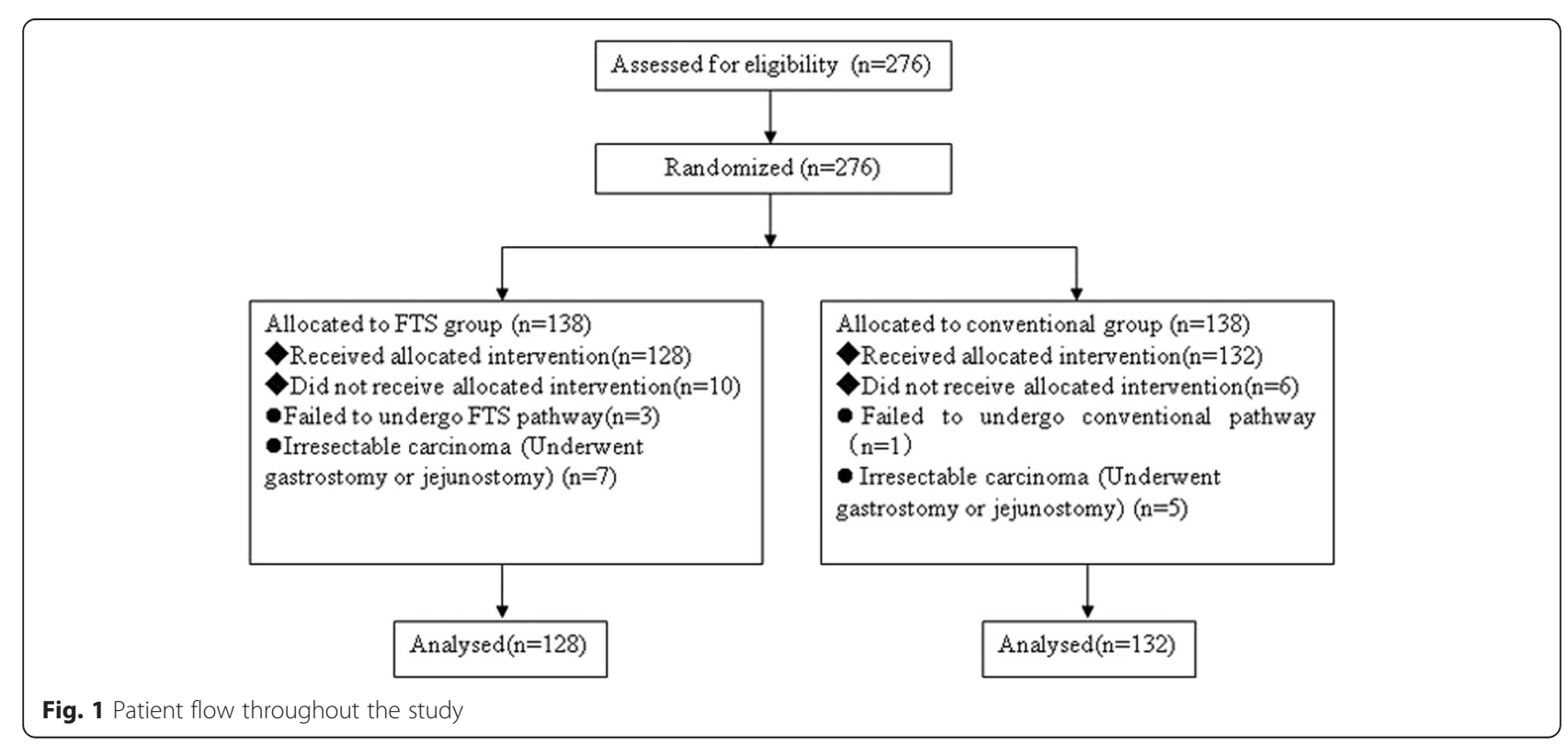


admitted; specifically, 138 patients were randomized to traditional protocol wards and 138 to the FTS surgery wards.

Ten patients in the FTS group and 6 patients in the conventional group failed to undergo FTS and

Table 1 Characteristics of patients and their diagnosis

\begin{tabular}{|c|c|c|c|}
\hline Characteristics & $\begin{array}{l}\text { FTS group } \\
(n=128)\end{array}$ & $\begin{array}{l}\text { Conventional } \\
\text { group }(n=132)\end{array}$ & $P$ value \\
\hline Median age & $56.43 \pm 13.28$ & $55.72 \pm 10.34$ & 0.252 \\
\hline Gender & & & 0.973 \\
\hline Male & $103(80.5)$ & $106(80.3)$ & \\
\hline Female & $25(19.5)$ & $26(19.7)$ & \\
\hline Weight (kg) & $67.53 \pm 14.37$ & $66.45 \pm 13.56$ & 0.448 \\
\hline $\mathrm{BMI}\left(\mathrm{kg} / \mathrm{m}^{2}\right)$ & $22.53 \pm 2.85$ & $22.89 \pm 2.56$ & 0.272 \\
\hline Operating time (min) & $168.98 \pm 30.62$ & $172.33 \pm 24.67$ & 0.438 \\
\hline Blood loss (ml) & $302.54 \pm 88.48$ & $312.33 \pm 76.73$ & 0.727 \\
\hline Operative incision & & & 0.749 \\
\hline One & $44(34.4)$ & $48(36.4)$ & \\
\hline Two & $58(45.3)$ & $62(46.9)$ & \\
\hline Three & $26(20.3)$ & $22(16.7)$ & \\
\hline TNM & & & 0.773 \\
\hline । & $39(30.5)$ & $36(27.2)$ & \\
\hline$\|$ & $71(55.4)$ & 79 (59.8) & \\
\hline III & $18(14.1)$ & $17(12.8)$ & \\
\hline IV & $0(0)$ & $0(0)$ & \\
\hline Pathology & & & 0.737 \\
\hline Adenocarcinoma & $7(5.5)$ & $8(6.1)$ & \\
\hline Squamous cell carcinoma & $116(90.6)$ & $121(91.6)$ & \\
\hline Other & $5(3.9)$ & $3(2.3)$ & \\
\hline Tumor location & & & 0.921 \\
\hline Upper esophagus & $12(9.4)$ & $14(10.6)$ & \\
\hline Mid esophagus & $73(57.0)$ & $76(57.6)$ & \\
\hline Distal esophagus & $43(33.6)$ & $42(31.8)$ & \\
\hline Neoadjuvant therapy & & & 0.988 \\
\hline Yes & $68(53.1)$ & $70(53.0)$ & \\
\hline No & $60(46.9)$ & $62(47.0)$ & \\
\hline Neoadjuvant regimen & & & 0.923 \\
\hline $\begin{array}{l}\text { Neoadjuvant } \\
\text { chemoradiotherapy }\end{array}$ & $27(39.7)$ & $25(35.7)$ & \\
\hline Neoadjuvant chemotherapy & $41(60.3)$ & $45(64.3)$ & \\
\hline $\begin{array}{l}\text { PCR after Neoadjuvant } \\
\text { therapy }\end{array}$ & $15(22.1)$ & $17(24.2)$ & 0.776 \\
\hline Surgical approach & & & 0.953 \\
\hline Conventional thoracotomy & $62(48.4)$ & $66(50.0)$ & \\
\hline Hybrid VATS & $41(32.0)$ & $42(31.8)$ & \\
\hline Pure VATS & 25 (19.6) & 24 (18.2) & \\
\hline
\end{tabular}

Variables were expressed as the mean \pm SD $p C R$ pathologic complete response rates conventional pathway. Most of them did not undergo esophagectomy as expected. The final study population included 260 patients (Fig. 1). The relevant characteristics of patients and the types of surgery are listed in Table 1. Gastroscope and barium meal of the upper gastrointestinal tract were systematically performed for tumors before operations. All patients underwent further work-up to assess the medical operability. This included evaluation of pulmonary and cardiac function, cervical and abdominal ultrasonography, chest computed tomography, and hematological examinations.

The FTS pathway used was developed by our cooperation team based on a previous protocol [2]. The principles of the FTS and conventional pathways are described in Table 2, and the principles of the postoperative FTS and conventional pathways are described in Table 3. The

Table 2 Principles of FTS pathway and conventional pathway

\begin{tabular}{lll}
\hline & FTS pathway & $\begin{array}{l}\text { Conventional } \\
\text { pathway }\end{array}$ \\
\hline $\begin{array}{l}\text { Preoperative } \\
\text { education }\end{array}$ & $\begin{array}{l}\text { Patients were educated } \\
\text { systematically by the } \\
\text { esophageal clinical nurse consultant; }\end{array}$ & $\begin{array}{l}\text { Patients were } \\
\text { educated in the }\end{array}$ \\
& standard manner
\end{tabular}

Day before surgery

\begin{tabular}{|c|c|c|}
\hline Diet & $\begin{array}{l}\text { Last drink } 2 \mathrm{~h} \text { and diet } 6 \mathrm{~h} \\
\text { before operation }\end{array}$ & $\begin{array}{l}\text { Last drink and } \\
\text { diet at midnight }\end{array}$ \\
\hline $\begin{array}{l}\text { Fructose } \\
\text { and protein } \\
\text { loading }\end{array}$ & Yes & No \\
\hline \multicolumn{3}{|l|}{$\begin{array}{l}\text { Day of } \\
\text { surgery }\end{array}$} \\
\hline $\begin{array}{l}\text { Nasogastric } \\
\text { tube }\end{array}$ & $\begin{array}{l}\text { No routine use of nasogastric } \\
\text { tube }\end{array}$ & $\begin{array}{l}\text { Routine use of } \\
\text { nasogastric tube }\end{array}$ \\
\hline $\begin{array}{l}\text { Pre- } \\
\text { anesthetic } \\
\text { medication }\end{array}$ & No & Diazepam 10 \\
\hline Anesthesia & $\begin{array}{l}\text { General anesthesia + Epidural } \\
\text { anesthesia; }\end{array}$ & $\begin{array}{l}\text { General } \\
\text { anesthesia; }\end{array}$ \\
\hline Maintaining & Yes & No \\
\hline
\end{tabular}

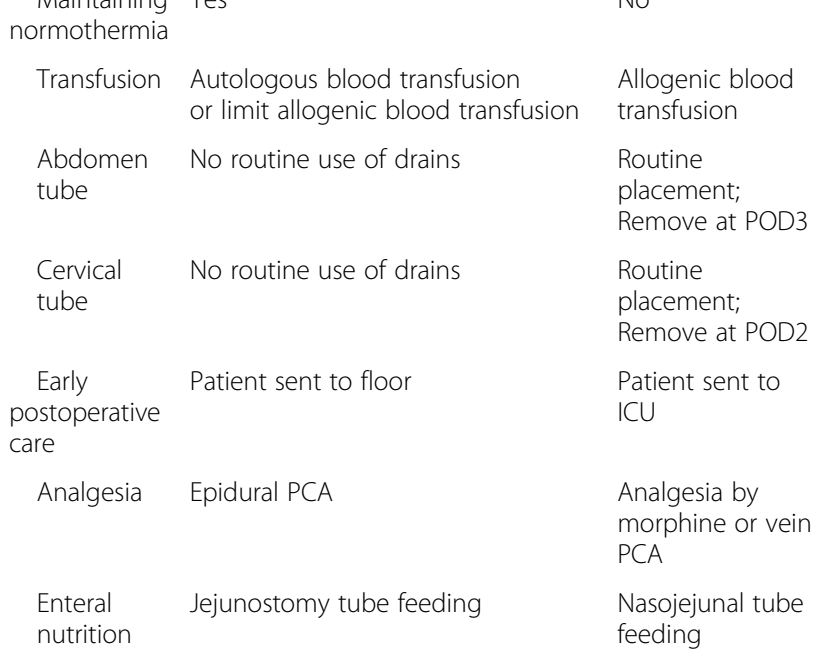


Table 3 Daily guideline of postoperative care of patients with FTS pathway vs conventional pathway

\begin{tabular}{|c|c|c|}
\hline Day & FTS pathway & Conventional pathway \\
\hline POD1 & $\begin{array}{l}\text { Jejunostomy tube feeding } 500 \mathrm{~mL} \text { (starting at } 20 \mathrm{~mL} / \mathrm{h} \text { ) } \\
\text { Early postoperative mobilization program } \\
\text { (>2 h out of bed) } \\
\text { Physical therapy and nebulizers } \\
\text { Remove urine catheter } \\
\text { Head of bed put at } 30^{\circ} \\
\text { Supply albumin } \\
\text { Chest tube to suction } \\
\text { Promoted to lung recruitment }\end{array}$ & $\begin{array}{l}\text { Total parenteral nutrition } \\
\text { Bed rest } \\
\text { Gastrointestinal decompression } \\
\text { Closed thoracic drainage }\end{array}$ \\
\hline POD2 & $\begin{array}{l}\text { Jejunostomy tube feeding } 1000 \mathrm{~mL}(40 \mathrm{~mL} / \mathrm{h}) \\
\text { Chest tube to suction } \\
\text { Expand mobilization ( }>4 \mathrm{~h} \text { out of bed) } \\
\text { Continue physical therapy and nebulizers } \\
\text { Continue supply albumin }\end{array}$ & $\begin{array}{l}\text { Nasojejunal tube feeding } 500 \mathrm{~mL} \text { (starting at } 20 \mathrm{~mL} / \mathrm{h} \text { ) } \\
\text { Remove urine catheter } \\
\text { With help, sit in the chair } 2 \text { times during the day for at least } 30 \text { min each time } \\
\text { Gastrointestinal decompression } \\
\text { Closed thoracic drainage }\end{array}$ \\
\hline POD3 & $\begin{array}{l}\text { Jejunostomy tube feeding } 1500 \mathrm{~mL}(60-80 \mathrm{~mL} / \mathrm{h}) \\
\text { Remove chest tube } \\
\text { Remove epidural catheter } \\
\text { Expand mobilization ( }>6 \mathrm{~h} \text { out of bed) } \\
\text { Continue physical therapy and nebulizers } \\
\text { Continue supply albumin }\end{array}$ & $\begin{array}{l}\text { Nasojejunal tube feeding } 1000 \mathrm{~mL}(40 \mathrm{~mL} / \mathrm{h}) \\
\text { Sit in the chair } 3 \text { times for at least } 30-60 \mathrm{~min} \text { each time. } \\
\text { With help, walk twice in the hallway. } \\
\text { Do deep breathing exercise } \\
\text { Remove nasogastric tube } \\
\text { Closed thoracic drainage }\end{array}$ \\
\hline POD4 & $\begin{array}{l}\text { Gastrograffin opacification of upper gastrointestine } \\
\text { If swallow shows no leak, advance patient to oral drink } \\
\text { Jejunostomy tube feeding } 1500 \mathrm{~mL}(60-80 \mathrm{~mL} / \mathrm{h}) \\
\text { Continue physical therapy and nebulizers } \\
\text { Education on aspiration precaution } \\
\text { Education on chewing and swallowing }\end{array}$ & $\begin{array}{l}\text { Nasojejunal tube feeding } 1000 \mathrm{~mL}(40 \mathrm{~mL} / \mathrm{h}) \\
\text { Sit in the chair } 3 \text { times today for at least } 30-60 \text { min each time. } \\
\text { Walk the length of the hallway } 3 \text { times } \\
\text { Continue to do breathing exercises } \\
\text { Closed thoracic drainage }\end{array}$ \\
\hline POD5 & $\begin{array}{l}\text { Jejunostomy tube feeding } 1500 \mathrm{~mL}(60-80 \mathrm{~mL} / \mathrm{h}) \\
\text { Advance patient to a full liquid diet } \\
\text { Continue aspiration precautions } \\
\text { Continue physical therapy and nebulizers }\end{array}$ & $\begin{array}{l}\text { Nasojejunal tube feeding } 1500 \mathrm{~mL}(60-80 \mathrm{~mL} / \mathrm{h}) \\
\text { Walk the length of the hallway } 4-5 \text { times. Sit in the chair } 3 \text { times today for at } \\
\text { least } 30-60 \mathrm{~min} \\
\text { Continue to do breathing exercises }\end{array}$ \\
\hline POD6 & $\begin{array}{l}\text { Increase liquid diet } \\
\text { Decrease jejunostomy tube feeding } \\
(500 \mathrm{ml} \text { or } 1000 \mathrm{ml}) \\
\text { Continue aspiration precautions } \\
\text { Continue physical therapy and nebulizers }\end{array}$ & $\begin{array}{l}\text { Nasojejunal tube feeding } 1500 \mathrm{~mL}(60-80 \mathrm{~mL} / \mathrm{h}) \\
\text { Remove chest tube } \\
\text { Walk the length of the hallway } 4-5 \text { times. Sit in the chair } 3 \text { times today for at } \\
\text { least } 30-60 \mathrm{~min} \\
\text { Continue to do breathing exercises }\end{array}$ \\
\hline POD7 & $\begin{array}{l}\text { Remove jejunostomy tube } \\
\text { Full liquid diet } \\
\text { Discharge home on soft diet and liquid diet } \\
\text { Continue aspiration precautions }\end{array}$ & $\begin{array}{l}\text { Gastrograffin opacification of upper gastrointestine } \\
\text { If swallow shows no leak, advance patient to oral drink } \\
\text { Nasojejunal tube feeding } 1500 \mathrm{~mL}(60-80 \mathrm{~mL} / \mathrm{h}) \\
\text { Expand mobilization ( }>4 \text { h out of bed) } \\
\text { Continue to do breathing exercises }\end{array}$ \\
\hline POD8 & & $\begin{array}{l}\text { Increase liquid diet } \\
\text { Decrease jejunostomy tube feeding ( } 500 \mathrm{ml} \text { or } 1000 \mathrm{ml}) \\
\text { Expand mobilization ( }>6 \mathrm{~h} \text { out of bed) } \\
\text { Continue to do breathing exercises }\end{array}$ \\
\hline POD9 & & $\begin{array}{l}\text { Remove nasojejunal tube } \\
\text { Full liquid diet } \\
\text { Expand mobilization ( }>6 \text { h out of bed) } \\
\text { Continue to do breathing exercises }\end{array}$ \\
\hline $\begin{array}{l}\text { POD10- } \\
11\end{array}$ & & $\begin{array}{l}\text { Soft diet and liquid diet } \\
\text { Nearly out of bed } \\
\text { Observe whether there is delayed anastomotic leakage }\end{array}$ \\
\hline POD12 & & Discharge home on soft diet and liquid diet \\
\hline
\end{tabular}

study was approved by the Research Ethics Committee of Harbin Medical University, and written informed consent was obtained from all subjects.

\section{Clinical parameters}

The post-operative hospital stay defined as time spent in the hospital from the day of operation to the day of hospital discharge, including readmission stay within 30 days postoperatively. The complications were defined as atrial arrhythmia, anastomotic leak, ileus, pneumonia, ARDS and incision infection. Readmission rate was also recorded. Pain while coughing, staying in bed or during exercise was judged by the patients three times daily until day 5 after surgery using the numeric rating scale 
Table 4 Comparison of outcome of two group

\begin{tabular}{llll}
\hline Outcomes & FTS group $(n=128)$ & Conventional group $(n=132)$ & $P$ value \\
\hline Postoperative hospital stay (d) & $7.62 \pm 1.38$ & $12.56 \pm 1.92$ & 0.000 \\
Hospitalization expenditure (RMB) & $35823.62 \pm 3598.81$ & $41032.73 \pm 4013.32$ & 0.000 \\
Incision pain scale (NRS) & $4.72 \pm 1.94$ & $7.66 \pm 1.59$ & 0.000 \\
Morbidity & $11(8.6)$ & $16(12.1)$ & 0.351 \\
$\quad$ Atrial arrhythmia & 2 & 3 & 1 \\
$\quad$ lleus & 0 & 4 & 3 \\
$\quad$ Pneumonia & 3 & 2 \\
Anastomotic leak & 2 & 3 \\
$\quad$ Incision infection & 2 & $2(1.5)$ \\
ARDS & 2 & $3(2.3)$ \\
Mortality & $2(1.6)$ & $3(2.3)$ & 1.000 \\
30-day readmission rate & & 1.000 \\
\hline
\end{tabular}

Variables were expressed as the mean \pm SD

The Numeric Rating Scale (NRS) is an 11-point (0-10) scale for patient self-reporting of pain. It is for adults and children 10 years old or older $R M B$ Ren Min Bi or China Yuan

( 0 , no pain to 10 , maximum pain). The perioperative hospital charges included surgery, anesthesia, drugs, auxiliary examination (including laboratory and radiology), and care costs, but didn't include neoadjuvant therapy costs.

\section{Protocol for esophageal cancer}

The diagnostic and therapeutic protocols for patients with esophageal cancer at the authors' institution is based on NCCN Guidelines version 1.2013 (page 3637). Since the R0-resection rate and long-term outcome of patients with T3/T4 tumors is poor with primary resection, multimodal therapeutic concepts with preoperative chemotherapy or combined radiochemotherapy or both are employed in these patients.

Table 5 Comparison of inflammatory markers in two groups

\begin{tabular}{llll}
\hline Factor and time & $\begin{array}{l}\text { FTS group } \\
(n=128)\end{array}$ & $\begin{array}{l}\text { Conventional group } \\
(n=132)\end{array}$ & $P$ value \\
\hline IL-6 (ng/L) & & & \\
Before surgery & $53.83 \pm 21.66$ & $55.73 \pm 20.37$ & 0.585 \\
POD1 & $121.74 \pm 22.57$ & $138.77 \pm 21.53^{*}$ & 0.000 \\
POD3 & $142.37 \pm 25.09$ & $154.90 \pm 24.33^{*}$ & 0.035 \\
POD7 & $116.70 \pm 22.39$ & $122.79 \pm 25.64$ & 0.412 \\
CRP $(\mu g / L)$ & & & \\
Before surgery & $4.97 \pm 1.33$ & $4.85 \pm 1.43$ & 1.000 \\
POD1 & $65.57 \pm 13.37$ & $74.61 \pm 14.71^{*}$ & 0.034 \\
POD3 & $136.79 \pm 23.34$ & $155.38 \pm 28.75^{*}$ & 0.012 \\
POD7 & $51.83 \pm 17.66$ & $62.36 \pm 18.37^{*}$ & 0.042 \\
\hline
\end{tabular}

Variables were expressed as the mean \pm SD

* $P<0.05$

\section{Pro-inflammatory parameters}

Peripheral venous blood samples were collected in serum collection tubes (Kabe) and were subsequently centrifuged at $300 \times \mathrm{g}$ for $15 \mathrm{~min}$ at $4{ }^{\circ} \mathrm{C}$ and serum samples were subsequently stored at $-80{ }^{\circ} \mathrm{C}$ until assayed for IL-6.

Circulating serum IL-6 levels were determined using sandwich enzyme-linked immunosorbent assay (Biosource, Nivelles, Belgium) as described by the manufacturer. CRP was measured with the immunoturbidimetric method (Olympus, Hamburg, Germany).

\section{Immunological parameters}

Blood samples were taken on the day before surgery as well as on days 1, 3 and 5 after surgery. All blood samples were taken from peripheral veins at 6 a.m., before breakfast. The humoral immunologic factors tested in our study included serum globulin, immunoglobulin G (IgG), immunoglobulin M (IgM), immunoglobulin A (IgA).

\section{Lymphocyte subpopulation parameters}

Lymphocyte subpopulations (CD3, CD4, and CD8 lymphocytes, and the $\mathrm{CD} 4 / \mathrm{CD} 8$ ratio) were determined by flow cytometry (Becton Dickinson, San Jose, CA, USA). The monoclonal antibodies used for immunophenotyping were purchased from Becton Dickinson and conjugated to the fluorochromes, fluorescein isothiocyanate or phycoerythrin. The fluorescence was measured using a FACScalibur (Becton Dickinson) within $60 \mathrm{~min}$ of processing of the samples. Fluorescent-activated cell sorting analysis was carried out on a FACScalibur flow cytometer. A minimum of 10,000 cells were measured for each determination. 
Table 6 Comparison of immunologic factors in two groups

\begin{tabular}{|c|c|c|c|}
\hline Factor and time & $\begin{array}{l}\text { FTS group } \\
(n=128)\end{array}$ & $\begin{array}{l}\text { Conventional group } \\
(n=132)\end{array}$ & $P$ value \\
\hline \multicolumn{4}{|l|}{ Globulin (g/l) } \\
\hline Before surgery & $28.37 \pm 3.93$ & $27.32 \pm 4.33$ & 0.943 \\
\hline POD1 & $22.74 \pm 3.93$ & $22.39 \pm 3.82$ & 1.000 \\
\hline POD3 & $25.66 \pm 2.94$ & $22.21 \pm 2.99^{*}$ & 0.038 \\
\hline POD7 & $29.95 \pm 3.85$ & $27.97 \pm 4.41$ & 0.537 \\
\hline \multicolumn{4}{|l|}{$\lg G(g / l)$} \\
\hline Before surgery & $14.38 \pm 2.78$ & $15.33 \pm 3.79$ & 0.573 \\
\hline POD1 & $8.97 \pm 1.79$ & $6.11 \pm 1.38^{*}$ & 0.033 \\
\hline POD3 & $11.02 \pm 3.53$ & $8.17 \pm 2.94^{*}$ & 0.002 \\
\hline POD7 & $14.53 \pm 3.81$ & $13.02 \pm 3.73$ & 0.741 \\
\hline \multicolumn{4}{|l|}{$\lg A(g / l)$} \\
\hline Before surgery & $2.79 \pm 0.52$ & $2.98 \pm 0.35$ & 0.757 \\
\hline POD1 & $1.81 \pm 0.43$ & $1.65 \pm 0.17^{*}$ & 0.012 \\
\hline POD3 & $2.08 \pm 0.54$ & $1.76 \pm 0.47^{*}$ & 0.003 \\
\hline POD7 & $2.58 \pm 0.47$ & $2.62 \pm 0.39$ & 0.637 \\
\hline \multicolumn{4}{|l|}{$\lg M(g / l)$} \\
\hline Before surgery & $1.21 \pm 0.35$ & $1.24 \pm 0.44$ & 1.000 \\
\hline POD1 & $0.82 \pm 0.39$ & $0.89 \pm 0.43$ & 0.964 \\
\hline POD3 & $0.75 \pm 0.22$ & $0.77 \pm 0.31$ & 0.543 \\
\hline POD7 & $1.18 \pm 0.59$ & $1.23 \pm 0.48$ & 0.424 \\
\hline \multicolumn{4}{|l|}{ CD3 } \\
\hline Before surgery & $55.99 \pm 2.72$ & $57.83 \pm 2.64$ & 0.813 \\
\hline POD1 & $49.92 \pm 2.75$ & $46.01 \pm 2.83^{*}$ & 0.042 \\
\hline POD3 & $51.83 \pm 2.42$ & $48.02 \pm 2.51^{*}$ & 0.019 \\
\hline POD7 & $55.05 \pm 2.69$ & $53.83 \pm 2.71$ & 0.737 \\
\hline \multicolumn{4}{|l|}{ CD4 } \\
\hline Before surgery & $45.58 \pm 3.92$ & $44.97 \pm 4.32$ & 0.958 \\
\hline POD1 & $33.26 \pm 4.72$ & $30.37 \pm 5.21^{*}$ & 0.039 \\
\hline POD3 & $39.39 \pm 4.81$ & $34.34 \pm 5.72^{*}$ & 0.012 \\
\hline POD7 & $43.76 \pm 4.38$ & $42.87 \pm 3.98$ & 0.887 \\
\hline \multicolumn{4}{|l|}{ CD8 } \\
\hline Before surgery & $26.73 \pm 4.85$ & $26.08 \pm 3.97$ & 1.000 \\
\hline POD1 & $23.72 \pm 4.33$ & $24.42 \pm 4.74$ & 0.958 \\
\hline POD3 & $23.76 \pm 3.83$ & $22.73 \pm 4.65$ & 0.832 \\
\hline POD7 & $28.73 \pm 4.38$ & $27.62 \pm 3.83$ & 0.732 \\
\hline \multicolumn{4}{|l|}{$\mathrm{CD} 4 / \mathrm{CD} 8$} \\
\hline Before surgery & $1.53 \pm 0.33$ & $1.48 \pm 0.42$ & 0.739 \\
\hline POD1 & $1.45 \pm 0.31$ & $1.22 \pm 0.45^{*}$ & 0.042 \\
\hline POD3 & $1.52 \pm 0.45$ & $1.39 \pm 0.30^{*}$ & 0.023 \\
\hline POD7 & $1.58 \pm 0.32$ & $1.53 \pm 0.54$ & 0.865 \\
\hline
\end{tabular}

Variables were expressed as the mean \pm SD

$* P<0.05$

\section{Discharge and follow-up}

Patients were discharged only if they could tolerate a semiliquid or soft diet and walk freely in the ward. Data were collected prospectively and retrieved from our database. Complete follow-up was available until 1 month after surgery.

\section{Statistical analysis}

Outcome data were analyzed with the use of repeat measurement ANOVA for continuous variables and chisquare test or Fisher's exact test for categorical variables. All analyses were performed with the statistical package SPSS (version 13.0; Chicago, IL). A $P$ value of $<0.05$ was considered significant.

\section{Results}

In all, 260 patients finished the study, including 128 patients in the FTS group and 132 patients in the conventional group. Ten patients were excluded from the FTS group and six patients from the conventional group (Fig. 1). No significant differences were observed in sex, age, weight, BMI, operating time, blood loss, operative incision, tumor TNM stage, tumor pathology, tumor location and neoadjuvant therapy between the two groups (Table 1).

\section{Clinical parameters}

Postoperative hospital stay in patients randomized to the FTS group was significantly shorter than in the conventional group $(P<0.05)$. The mean charge for perioperative hospital stay was $35823.62 \pm 3598.81$ renminbi (RMB) for the FTS group, which was significantly less than the cost of $41032.73 \pm 4013.32$ RMB for the conventional group $(P<0.05)$. Incision pain according to the Numeric Rating Scale was lower in patients of the FTS group than in those of the conventional group $(P<0.05)$. And we had compared the degree of pain among three different surgical approaches: pure video-assisted thoracic surgery (VATS), hybrid VATS, and conventional thoracotomy. In the early postoperative period, pure VATS was shown to be the least painful of the three surgical approaches. No statistically significant differences were detected in postoperative complications between the two groups $(P<0.05)$. There was, however, a trend toward more postoperative complications $(9.8 \%)$ in patients undergoing conventional pathway (Table 4). According to Clavien-Dindo classification, 11 (8.6 \%) patients in FTS group and 16 (12.1\%) patients in conventional group suffered stageI, II and III complications respectively. Two patient in FTS group and three patient in the conventional group was diagnosed atrial arrhythmia by an ECG recording (I). Two patient in FTS group and two patient in the conventional group showed incision infection (I). One patient in the conventional group developed postoperative paralytic ileus and 
Table 7 Comparison of inflammatory markers and immunologic factors in two groups without neoadjuvant

\begin{tabular}{|c|c|c|c|}
\hline Factor and time & $\begin{array}{l}\text { FTS group } \\
(n=60)\end{array}$ & $\begin{array}{l}\text { Conventional group } \\
(n=62)\end{array}$ & $P$ value \\
\hline \multicolumn{4}{|l|}{ IL-6 (ng/L) } \\
\hline Before surgery & $52.13 \pm 25.54$ & $54.67 \pm 22.36$ & 0.651 \\
\hline POD1 & $123.43 \pm 20.73$ & $139.26 \pm 22.92^{*}$ & 0.007 \\
\hline POD3 & $144.05 \pm 26.39$ & $156.25 \pm 25.38^{*}$ & 0.032 \\
\hline POD7 & $117.23 \pm 21.29$ & $123.36 \pm 25.56$ & 0.321 \\
\hline \multicolumn{4}{|l|}{ CRP (mg/L) } \\
\hline Before surgery & $4.92 \pm 1.53$ & $4.83 \pm 1.72$ & 0.953 \\
\hline POD1 & $66.37 \pm 12.93$ & $75.52 \pm 14.88^{*}$ & 0.023 \\
\hline POD3 & $138.84 \pm 22.04$ & $156.58 \pm 29.21^{*}$ & 0.019 \\
\hline POD7 & $53.84 \pm 16.95$ & $64.06 \pm 16.74^{*}$ & 0.031 \\
\hline \multicolumn{4}{|l|}{ Globulin (g/l) } \\
\hline Before surgery & $28.82 \pm 3.93$ & $27.97 \pm 5.21$ & 0.643 \\
\hline POD1 & $22.25 \pm 3.83$ & $21.09 \pm 3.90$ & 0.231 \\
\hline POD3 & $25.72 \pm 3.08$ & $22.68 \pm 2.89^{*}$ & 0.026 \\
\hline POD7 & $28.56 \pm 2.25$ & $27.74 \pm 4.04$ & 0.447 \\
\hline \multicolumn{4}{|l|}{$\lg G(g / l)$} \\
\hline Before surgery & $15.82 \pm 2.98$ & $14.18 \pm 3.69$ & 0.585 \\
\hline POD1 & $8.87 \pm 1.65$ & $6.32 \pm 1.19^{*}$ & 0.025 \\
\hline POD3 & $10.88 \pm 3.37$ & $7.94 \pm 2.87^{*}$ & 0.000 \\
\hline POD7 & $14.51 \pm 2.83$ & $13.97 \pm 3.63$ & 0.231 \\
\hline \multicolumn{4}{|l|}{$\lg A(g / l)$} \\
\hline Before surgery & $2.76 \pm 0.33$ & $2.85 \pm 0.27$ & 0.654 \\
\hline POD1 & $1.71 \pm 0.54$ & $1.45 \pm 0.14^{*}$ & 0.013 \\
\hline POD3 & $1.98 \pm 0.47$ & $1.67 \pm 0.52^{*}$ & 0.002 \\
\hline POD7 & $2.53 \pm 0.33$ & $2.42 \pm 0.38$ & 0.585 \\
\hline \multicolumn{4}{|l|}{$\lg M(g / l)$} \\
\hline Before surgery & $1.24 \pm 0.33$ & $1.19 \pm 0.46$ & 0.841 \\
\hline POD1 & $0.85 \pm 0.49$ & $0.81 \pm 0.32$ & 0.432 \\
\hline POD3 & $0.77 \pm 0.17$ & $0.71 \pm 0.26$ & 0.233 \\
\hline POD7 & $1.15 \pm 0.53$ & $1.21 \pm 0.50$ & 0.190 \\
\hline \multicolumn{4}{|l|}{ CD3+ } \\
\hline Before surgery & $57.92 \pm 2.63$ & $58.23 \pm 2.48$ & 0.764 \\
\hline POD1 & $48.87 \pm 2.51$ & $46.13 \pm 2.78^{*}$ & 0.047 \\
\hline POD3 & $51.17 \pm 2.20$ & $48.19 \pm 2.31^{*}$ & 0.013 \\
\hline POD7 & $55.59 \pm 2.28$ & $53.07 \pm 2.84$ & 0.230 \\
\hline \multicolumn{4}{|l|}{ CD4+ } \\
\hline Before surgery & $44.28 \pm 3.48$ & $44.73 \pm 4.52$ & 0.864 \\
\hline POD1 & $34.95 \pm 4.72$ & $31.07 \pm 5.09^{*}$ & 0.020 \\
\hline POD3 & $38.52 \pm 3.61$ & $34.54 \pm 5.22^{*}$ & 0.016 \\
\hline POD7 & $43.38 \pm 5.86$ & $42.48 \pm 3.84$ & 0.382 \\
\hline
\end{tabular}

Table 7 Comparison of inflammatory markers and immunologic factors in two groups without neoadjuvant (Continued)

\begin{tabular}{llll}
\hline CD4+/CD8+ & & \\
Before surgery & $1.64 \pm 0.32$ & $1.55 \pm 0.49$ & 0.872 \\
POD1 & $1.43 \pm 0.21$ & $1.20 \pm 0.51^{*}$ & 0.036 \\
POD3 & $1.54 \pm 0.55$ & $1.41 \pm 0.34^{*}$ & 0.018 \\
POD7 & $1.57 \pm 0.24$ & $1.51 \pm 0.28$ & 0.341 \\
\hline $\begin{array}{l}\text { Variables were expressed as the median } \pm \text { quartile } \\
{ }^{*} P<0.05\end{array}$
\end{tabular}

required reinsertion of a nasogastric tube, and this was resolved by restricting intake and parenteral nutrition (II). Three patients in FTS group and four patients in the conventional group had pneumonia and this was resolved by physical therapy and antibiotic treatment (II). Anastomotic leak occurred in two patient in FTS group and three patients in the conventional group, and this was resolved by endoscopic treatment (III). Two patients in FTS group and three patients in the conventional group had ARDS and were treated with mechanical ventilation in the Intensive Care Unit (IV).

\section{Pro-inflammatory parameters}

On PODs 1 and 3, statistically significant differences were found in levels of IL- 6 and CRP with the FTS group having lower levels than in the conventional group $(P<0.05)$. On POD 7 , the level of CRP was lower in the FTS group than that in the conventional group $(P$ $<0.05$ ) (Table 5).

\section{Immunological parameters}

There were no significant differences in the postoperativelevel and pre-operative level of IgM and CD8 between the two groups. On PODs 1 and 3, statistically significant differences were found in the levels of IgG, IgA, CD3, CD4 and CD4/CD8 ratio with the FTS group having higher levels than the conventional group (all $P<0.05$ ). On POD 3 , the level of serum globulin was higher in the FTS group than that in the conventional group $(P<0.05)$ (Table 6). We performed subgroup analysis based on neoadjuvant or not, as well as MIE (Minimally invasive esophagectomy) or not for avoiding bias, and we came to similar conclusions after data analysis (Tables 7, 8, 9 and 10).

\section{Discussion}

Recent clinical data indicate that FTS leads to shorter postoperative length of hospital stay, faster recovery of gastrointestinal function as well as reduced morbidity and mortality rates $[1,3,4]$. To date, no study has focused on the effects of FTS on immune function after esophagectomy for esophageal cancer. This study was initiated to determine whether FTS results in improved 
Table 8 Comparison of inflammatory markers and immunologic factors in two groups with neoadjuvant

\begin{tabular}{|c|c|c|c|}
\hline Factor and time & $\begin{array}{l}\text { FTS group } \\
(n=68)\end{array}$ & $\begin{array}{l}\text { Conventional group } \\
(n=70)\end{array}$ & $P$ value \\
\hline \multicolumn{4}{|l|}{ IL-6 (ng/L) } \\
\hline Before surgery & $50.57 \pm 21.45$ & $51.42 \pm 19.83$ & 0.979 \\
\hline POD1 & $119.54 \pm 18.62$ & $131.42 \pm 21.58^{*}$ & 0.004 \\
\hline POD3 & $138.42 \pm 22.73$ & $150.48 \pm 21.97^{*}$ & 0.043 \\
\hline POD7 & $112.52 \pm 19.43$ & $116.43 \pm 22.57$ & 0.573 \\
\hline \multicolumn{4}{|l|}{ CRP (mg/L) } \\
\hline Before surgery & $4.53 \pm 1.24$ & $4.45 \pm 1.29$ & 0.942 \\
\hline POD1 & $61.32 \pm 13.77$ & $70.52 \pm 11.56^{*}$ & 0.032 \\
\hline POD3 & $132.73 \pm 21.56$ & $150.49 \pm 25.72^{*}$ & 0.013 \\
\hline POD7 & $49.78 \pm 15.84$ & $60.43 \pm 16.38^{*}$ & 0.035 \\
\hline \multicolumn{4}{|l|}{ Globulin (g/l) } \\
\hline Before surgery & $25.67 \pm 3.34$ & $25.82 \pm 4.39$ & 1.000 \\
\hline POD1 & $21.43 \pm 3.63$ & $20.21 \pm 3.45$ & 0.760 \\
\hline POD3 & $24.76 \pm 3.82$ & $21.64 \pm 2.94^{*}$ & 0.023 \\
\hline POD7 & $25.73 \pm 3.35$ & $25.87 \pm 4.09$ & 0.848 \\
\hline \multicolumn{4}{|l|}{$\lg G(g / l)$} \\
\hline Before surgery & $13.76 \pm 3.13$ & $13.62 \pm 3.42$ & 0.858 \\
\hline POD1 & $7.42 \pm 1.42$ & $5.23 \pm 1.35^{*}$ & 0.031 \\
\hline POD3 & $9.42 \pm 3.53$ & $6.44 \pm 2.95^{*}$ & 0.001 \\
\hline POD7 & $12.56 \pm 2.67$ & $11.94 \pm 3.83$ & 0.656 \\
\hline \multicolumn{4}{|l|}{$\lg A(g / l)$} \\
\hline Before surgery & $2.19 \pm 0.29$ & $2.21 \pm 0.25$ & 0.769 \\
\hline POD1 & $1.61 \pm 0.37$ & $1.34 \pm 0.25^{*}$ & 0.017 \\
\hline POD3 & $1.85 \pm 0.42$ & $1.51 \pm 0.51^{*}$ & 0.004 \\
\hline POD7 & $2.04 \pm 0.37$ & $2.15 \pm 0.42$ & 0.753 \\
\hline \multicolumn{4}{|l|}{$\lg M(g / l)$} \\
\hline Before surgery & $1.14 \pm 0.31$ & $1.11 \pm 0.41$ & 0.893 \\
\hline POD1 & $0.71 \pm 0.39$ & $0.72 \pm 0.33$ & 0.957 \\
\hline POD3 & $0.67 \pm 0.22$ & $0.64 \pm 0.32$ & 0.873 \\
\hline POD7 & $1.09 \pm 0.43$ & $1.10 \pm 0.42$ & 0.673 \\
\hline \multicolumn{4}{|l|}{ CD3+ } \\
\hline Before surgery & $55.62 \pm 2.43$ & $56.82 \pm 2.58$ & 0.875 \\
\hline POD1 & $46.73 \pm 2.52$ & $44.09 \pm 2.03^{*}$ & 0.043 \\
\hline POD3 & $49.82 \pm 2.43$ & $46.17 \pm 2.35^{*}$ & 0.033 \\
\hline POD7 & $53.85 \pm 2.05$ & $54.04 \pm 2.73$ & 0.482 \\
\hline \multicolumn{4}{|l|}{ CD4+ } \\
\hline Before surgery & $42.43 \pm 3.57$ & $42.48 \pm 4.92$ & 0.803 \\
\hline POD1 & $32.52 \pm 4.13$ & $29.12 \pm 5.02^{*}$ & 0.025 \\
\hline POD3 & $35.32 \pm 3.90$ & $32.55 \pm 5.02^{*}$ & 0.013 \\
\hline POD7 & $41.42 \pm 5.24$ & $40.98 \pm 4.27$ & 0.484 \\
\hline
\end{tabular}

Table 8 Comparison of inflammatory markers and immunologic factors in two groups with neoadjuvant (Continued)

\begin{tabular}{llll}
\hline CD4+/CD8+ & & \\
Before surgery & $1.52 \pm 0.41$ & $1.55 \pm 0.45$ & 0.842 \\
POD1 & $1.33 \pm 0.36$ & $1.11 \pm 0.41^{*}$ & 0.027 \\
POD3 & $1.47 \pm 0.56$ & $1.32 \pm 0.37^{*}$ & 0.025 \\
POD7 & $1.50 \pm 0.36$ & $1.52 \pm 0.29$ & 0.562 \\
\hline $\begin{array}{l}\text { Variables } \\
* P<0.05\end{array}$
\end{tabular}

clinical and immunological outcome of patients undergoing esophagectomy for esophageal cancer.

The normal inflammatory response, more commonly known as the stress response, was first described by Sir David Cuthbertson [5]. Despite variability in the intensity of the stress response, the timeline of events remains remarkably similar, with few exceptions. Virtually all mediators of inflammation and metabolism peak about postinjury day 2 and then return to baseline levels by postinjury days $6-7$. The inflammatory response may obviously be important for wound healing and resistance to infection, but on the other hand may have undesirable effects by enhancing pain and leading to fatigue and sleep disturbances [6]. Inflammation is triggered when innate immune cells detect infection or tissue injury. We found most of immune markers decreased under condition of the increase of pro-inflammatory cytokines. This research into the mechanisms that immune impact may provide a novel therapeutic pathway that can alter the nature and time course of the stress response.

Perioperative intervention improvements that might be contributed to the immunologic protection, including taking a carbohydrate rich drink before surgery, early enteral nutrition and epidural analgesia. Before surgery, patients often already have poor nutritional status and low immune function. For patients with esophageal cancer, their nutritional status will be worsened after surgeries, along with the decrease of the cellular and humoral immunity [7]. Some studies indicated that taking a carbohydraterich drink before surgery could reduce the endocrine catabolic response and improve insulin resistance, improving surgical results and hastening recovery $[8,9]$. Gut is regarded as a central organ after surgical stress; also, among the intestinal mucosal barrier functions, immune barrier plays an important role. the functions of small intestine often return normal 6-12 h after the surgery, which supports the early application of enteral nutrition (EN) after surgery [10]. Clinically, EN is applied to facilitate the improvement of nutritional status, restoration of immune function, and protection of intestinal mucosal barrier after the surgeries. A recent study verified that partial EN support during perioperation will not only improve the postoperative nutritional 
Table 9 Comparison of inflammatory markers and immunologic factors in two groups without MIE

\begin{tabular}{|c|c|c|c|}
\hline Factor and time & $\begin{array}{l}\text { FTS group } \\
(n=63)\end{array}$ & $\begin{array}{l}\text { Conventional group } \\
(n=65)\end{array}$ & $P$ value \\
\hline \multicolumn{4}{|l|}{ IL-6 (ng/L) } \\
\hline Before surgery & $53.26 \pm 24.18$ & $53.58 \pm 23.14$ & 0.842 \\
\hline POD1 & $123.73 \pm 22.69$ & $139.42 \pm 24.78^{*}$ & 0.006 \\
\hline POD3 & $143.31 \pm 25.42$ & $155.79 \pm 24.42^{*}$ & 0.043 \\
\hline POD7 & $117.73 \pm 22.45$ & $123.57 \pm 23.84$ & 0.571 \\
\hline \multicolumn{4}{|l|}{ CRP (mg/L) } \\
\hline Before surgery & $4.94 \pm 1.48$ & $4.86 \pm 1.32$ & 0.943 \\
\hline POD1 & $66.42 \pm 13.73$ & $75.75 \pm 13.57^{*}$ & 0.032 \\
\hline POD3 & $137.76 \pm 24.73$ & $156.79 \pm 27.42^{*}$ & 0.015 \\
\hline POD7 & $52.75 \pm 15.79$ & $63.73 \pm 15.2^{*}$ & 0.042 \\
\hline \multicolumn{4}{|l|}{ Globulin (g/l) } \\
\hline Before surgery & $27.82 \pm 3.59$ & $28.71 \pm 5.33$ & 0.875 \\
\hline POD1 & $21.63 \pm 3.54$ & $21.79 \pm 3.82$ & 0.941 \\
\hline POD3 & $25.59 \pm 3.14$ & $22.79 \pm 2.98^{*}$ & 0.043 \\
\hline POD7 & $28.73 \pm 3.08$ & $27.95 \pm 4.24$ & 0.545 \\
\hline \multicolumn{4}{|l|}{$\lg G(g / l)$} \\
\hline Before surgery & $14.59 \pm 3.28$ & $13.97 \pm 3.82$ & 0.833 \\
\hline POD1 & $8.93 \pm 1.59$ & $6.47 \pm 1.25^{*}$ & 0.034 \\
\hline POD3 & $10.51 \pm 3.56$ & $7.82 \pm 2.96^{*}$ & 0.000 \\
\hline POD7 & $13.75 \pm 2.97$ & $13.66 \pm 3.32$ & 0.741 \\
\hline \multicolumn{4}{|l|}{$\lg A(g / l)$} \\
\hline Before surgery & $2.65 \pm 0.41$ & $2.75 \pm 0.32$ & 1.000 \\
\hline POD1 & $1.78 \pm 0.49$ & $1.41 \pm 0.25^{*}$ & 0.009 \\
\hline POD3 & $1.94 \pm 0.46$ & $1.65 \pm 0.43^{*}$ & 0.004 \\
\hline POD7 & $2.43 \pm 0.35$ & $2.49 \pm 0.41$ & 0.842 \\
\hline \multicolumn{4}{|l|}{$\lg M(g / l)$} \\
\hline Before surgery & $1.26 \pm 0.41$ & $1.21 \pm 0.33$ & 0.892 \\
\hline POD1 & $0.83 \pm 0.38$ & $0.85 \pm 0.36$ & 0.731 \\
\hline POD3 & $0.72 \pm 0.19$ & $0.71 \pm 0.22$ & 1.000 \\
\hline POD7 & $1.19 \pm 0.49$ & $1.24 \pm 0.42$ & 0.766 \\
\hline \multicolumn{4}{|l|}{ CD3+ } \\
\hline Before surgery & $58.03 \pm 2.52$ & $57.43 \pm 2.67$ & 0.852 \\
\hline POD1 & $48.93 \pm 2.47$ & $45.89 \pm 2.49^{*}$ & 0.048 \\
\hline POD3 & $51.67 \pm 2.33$ & $47.87 \pm 2.52^{*}$ & 0.011 \\
\hline POD7 & $54.68 \pm 2.32$ & $53.25 \pm 2.93$ & 0.473 \\
\hline \multicolumn{4}{|l|}{ CD4+ } \\
\hline Before surgery & $44.37 \pm 3.52$ & $44.52 \pm 4.31$ & 0.768 \\
\hline POD1 & $36.43 \pm 4.28$ & $32.66 \pm 5.14^{*}$ & 0.028 \\
\hline POD3 & $39.13 \pm 4.52$ & $33.95 \pm 5.38^{*}$ & 0.004 \\
\hline POD7 & $42.57 \pm 4.38$ & $42.64 \pm 3.95$ & 1.000 \\
\hline
\end{tabular}

Table 9 Comparison of inflammatory markers and immunologic factors in two groups without MIE (Continued)

\begin{tabular}{llll}
\hline CD4+/CD8+ & & \\
Before surgery & $1.59 \pm 0.41$ & $1.54 \pm 0.43$ & 0.892 \\
POD1 & $1.47 \pm 0.23$ & $1.22 \pm 0.41^{*}$ & 0.032 \\
POD3 & $1.51 \pm 0.45$ & $1.40 \pm 0.51^{*}$ & 0.012 \\
POD7 & $1.54 \pm 0.29$ & $1.57 \pm 0.21$ & 0.842 \\
\hline $\begin{array}{l}\text { Variables were expressed as the median } \pm \text { quartile } \\
{ }^{*} P<0.05\end{array}$
\end{tabular}

status and immune function, but also moderate the inflammatory response of gastric cancer patients after operative trauma [11]. Beier-Holgersen et al. [12] proved early postoperative enteral nutrition had an important influence on immediate unspecific cellular immunity and had an activating effect on specific cellular immunity. In our current randomized and controlled study, we provided EN with postoperative patients in the FTS group on POD1 and in the conventional group on POD2. The immune globulins (IgA and IgG) and $\mathrm{T}$ lymphocyte subsets (CD3, CD4 and CD4/CD8) at POD1, 3 were higher in the FTS group than them in the conventional group, showing a fast recovery of immunity. We hypothesized that the fast recovery of immunity might be ascribed to the fact that the earlier activation of the immune system by earlier EN after surgery.

It has been verified that nociception and proinflammatory cytokines play a mutual up-regulatory role [13]. Therefore, pain management may influence the immune response in the postoperative period. It has been reported that the alterations in lymphocyte subsets and the increase in white cell counts induced by surgery and general anesthesia can be prevented by epidural analgesia [14, 15]. Furthermore, Beilin et al. [16] reported that patients treated with patient-controlled analgesia (PCA) exhibited attenuated proinflammatory cytokine response in the postoperative period. Also Khaled et al. [17] showed that thoracic epidural analgesia reduced the systemic pro-inflammatory response and provided optimal post-operative pain relief. In major surgery, however, the effect of epidural anesthesia and analgesia on attenuation of the stress response and preservation of immune function is controversial.

The difference in immune function between the two groups was also statistically significant. There are several factors that may account for these differences. The duration of surgery and anesthesia, extent of tissue injury, and blood loss are usually great in patients undergoing esophagectomy. Blood transfusion is another factor in inducing immunosuppression. There is increasing evidence to suggest that perioperative blood transfusion may have an immunomodulatory effect. A previous study [18] of patients undergoing esophageal resection 
Table 10 Comparison of inflammatory markers and immunologic factors in two groups with MIE

\begin{tabular}{|c|c|c|c|}
\hline Factor and time & $\begin{array}{l}\text { FTS group } \\
(n=65)\end{array}$ & $\begin{array}{l}\text { Conventional group } \\
(n=67)\end{array}$ & $P$ value \\
\hline \multicolumn{4}{|l|}{ IL-6 (ng/L) } \\
\hline Before surgery & $52.33 \pm 24.37$ & $53.42 \pm 22.73$ & 0.764 \\
\hline POD1 & $119.34 \pm 21.57$ & $134.42 \pm 22.53^{*}$ & 0.005 \\
\hline POD3 & $140.05 \pm 25.63$ & $151.67 \pm 24.52^{*}$ & 0.035 \\
\hline POD7 & $113.72 \pm 22.42$ & $117.66 \pm 25.74$ & 0.152 \\
\hline \multicolumn{4}{|l|}{ CRP (mg/L) } \\
\hline Before surgery & $4.62 \pm 1.63$ & $4.53 \pm 1.57$ & 0.842 \\
\hline POD1 & $62.42 \pm 13.83$ & $71.42 \pm 14.32^{*}$ & 0.027 \\
\hline POD3 & $134.73 \pm 22.57$ & $153.82 \pm 25.62^{*}$ & 0.017 \\
\hline POD7 & $50.46 \pm 15.73$ & $61.43 \pm 15.66^{*}$ & 0.012 \\
\hline \multicolumn{4}{|l|}{ Globulin (g/l) } \\
\hline Before surgery & $27.72 \pm 3.55$ & $27.58 \pm 5.14$ & 0.942 \\
\hline POD1 & $23.57 \pm 3.73$ & $22.64 \pm 3.73$ & 0.543 \\
\hline POD3 & $25.42 \pm 3.95$ & $23.31 \pm 3.52^{*}$ & 0.021 \\
\hline POD7 & $28.04 \pm 2.76$ & $27.87 \pm 4.13$ & 0.735 \\
\hline \multicolumn{4}{|l|}{$\operatorname{lgG}(g / l)$} \\
\hline Before surgery & $14.63 \pm 2.57$ & $14.03 \pm 3.1$ & 0.872 \\
\hline POD1 & $9.43 \pm 1.25$ & $7.62 \pm 1.17^{*}$ & 0.028 \\
\hline POD3 & $11.82 \pm 3.52$ & $8.73 \pm 2.94^{*}$ & 0.002 \\
\hline POD7 & $14.42 \pm 2.76$ & $13.52 \pm 3.33$ & 0.542 \\
\hline \multicolumn{4}{|l|}{$\lg A(g / l)$} \\
\hline Before surgery & $2.57 \pm 0.31$ & $2.77 \pm 0.29$ & 0.767 \\
\hline POD1 & $1.83 \pm 0.41$ & $1.54 \pm 0.22^{*}$ & 0.015 \\
\hline POD3 & $1.99 \pm 0.35$ & $1.69 \pm 0.42^{*}$ & 0.000 \\
\hline POD7 & $2.55 \pm 0.32$ & $2.52 \pm 0.32$ & 0.652 \\
\hline \multicolumn{4}{|l|}{$\lg M(g / l)$} \\
\hline Before surgery & $1.28 \pm 0.31$ & $1.21 \pm 0.36$ & 0.853 \\
\hline POD1 & $0.94 \pm 0.43$ & $0.92 \pm 0.35$ & 0.482 \\
\hline POD3 & $0.87 \pm 0.21$ & $0.81 \pm 0.32$ & 0.353 \\
\hline POD7 & $1.25 \pm 0.46$ & $1.22 \pm 0.52$ & 0.320 \\
\hline \multicolumn{4}{|l|}{ CD3+ } \\
\hline Before surgery & $57.43 \pm 2.82$ & $58.12 \pm 2.73$ & 0.873 \\
\hline POD1 & $49.69 \pm 2.43$ & $47.02 \pm 2.57^{*}$ & 0.044 \\
\hline POD3 & $53.38 \pm 2.57$ & $49.93 \pm 2.65^{*}$ & 0.017 \\
\hline POD7 & $56.73 \pm 2.52$ & $56.48 \pm 2.49$ & 1.000 \\
\hline \multicolumn{4}{|l|}{ CD4+ } \\
\hline Before surgery & $44.52 \pm 3.46$ & $44.37 \pm 4.41$ & 1.000 \\
\hline POD1 & $35.87 \pm 4.15$ & $32.35 \pm 4.89^{*}$ & 0.022 \\
\hline POD3 & $39.98 \pm 3.73$ & $35.43 \pm 4.64^{*}$ & 0.013 \\
\hline POD7 & $44.73 \pm 5.02$ & $43.76 \pm 3.92$ & 0.859 \\
\hline
\end{tabular}

Table 10 Comparison of inflammatory markers and immunologic factors in two groups with MIE (Continued)

\begin{tabular}{llll}
\hline CD4+/CD8+ & & \\
Before surgery & $1.58 \pm 0.30$ & $1.52 \pm 0.42$ & 0.973 \\
POD1 & $1.49 \pm 0.24$ & $1.26 \pm 0.43^{*}$ & 0.031 \\
POD3 & $1.64 \pm 0.45$ & $1.45 \pm 0.28^{*}$ & 0.015 \\
POD7 & $1.56 \pm 0.32$ & $1.50 \pm 0.37$ & 0.458 \\
\hline $\begin{array}{l}\text { Variables were expressed as the median } \pm \text { quartile } \\
{ }^{*} P<0.05\end{array}$
\end{tabular}

for carcinoma has demonstrated a significantly worse prognosis for those receiving a blood transfusion independent of disease stage or the presence of major complications. It has been suggested that the immunosuppression induced by transfusion results from both an early unspecific immunosuppression mediated by monocytes and a later phase induced from increased suppressor $\mathrm{T}$ cell activity. Blood transfusion has been shown to lower the CD4 to CD8 ratio [19]. In addition, prostaglandin E2 levels are increased after transfusion [20]. This may result in a direct inhibition of interleukin-2 production from CD4 cells with subsequent effect, as interleukin-2 is obligatory for natural killer cell activity. In addition, it shows that transfusion of more than 3 units of blood can adversely affect survival [21]. Therefore, every effort should be made to limit the amount of blood transfused to the minimum requirement.

Cellular immunity is mediated by lymphocytes and transferred by the cells of immunized people. Humoral immunity is mediated by antibodies and transferred by the sera of immunized people. Impairment of cellular and humoral immune system may lead to infections secondary to surgery, progression of malign tumors, and emergence of opportunistic infections. IL-6 is known to be a major mediator of the acute-phase response and plasma levels of IL-6 are reportedly related to the severity of surgical trauma [22]. It can stimulate the liver to synthesize C-reactive protein (CRP), enhance inflammatory reaction by promoting $\mathrm{B}$ cell differentiation and antibody formation, and assist the $\mathrm{T}$ cells to produce the expressions of IL-2 and its receptor [23]. In our current study, no significant difference was found in both groups of immunological parameters before surgery and POD7. At PODs 1 and 3, the immune function indicators decreased in both groups. In the FTS group, the immune globulins (IgA and IgG) and $\mathrm{T}$ lymphocyte subsets (CD3, CD4 and CD4/CD8) were significantly higher than those in the conventional group $(P<0.05)$, whereas IL-6 and CRP were significantly lower $(P<0.05)$. Therefore, the FTS is helpful to improve the immune function in patients undergoing esophagectomy for esophageal cancer.

Another powerful technique to reduce inflammatory responses is decreasing the wound size by minimal invasive 
surgery. It is well established that this may reduce pain and inflammatory responses especially proinflammatory cytokines (IL-6 etc.) [24]. Inflammatory responses contribute to pain, fatigue and organ dysfunction. Minimally invasive surgery also reduces the inflammatory response, although the contribution that this plays in the context of fast-track programmes in esophageal surgery is difficult to interpret. We found that the immune function of patients is mildly affected by minimally invasive surgery. No significant differences were observed in immune function between the minimally invasive surgery group and the open surgery group. Of interest, a recent randomized blinded study by Basse et al. showed that FTS leads to similar clinical and functional results in patients undergoing open as well as laparoscopic colorectal resections [25]. This indicates that the clinical advantages of laparoscopic surgery may be of only minor importance for postoperative recovery if the concept of FTS surgery is used for patients after major surgery. Minimal invasive surgery on a procedure-specific basis therefore represent a major opportunity to further enhance recovery and reduce morbidity in the future, especially when combined with other aspects of the fast-track methodology.

Our results did not detect statistically significant changes in serum IgM and CD8 lymphocytes between the two groups. However, this does not mean that FTS has no effects on these factors, which may be explained by the time that blood samples were taken or the relatively small number of cases in our trial. The above factors may be differences between the two groups if we increase the time that blood samples were taken, or increase the amount of cases.

Only a small proportion of patients in our study underwent Pure VATS surgery. We have not enough evidence to demonstrate the effect of minimally invasive surgery on immunity. Therefore, the changes of immune indexes by laparoscopic and thoracoscopic surgery needs to be investigated in further studies.

\section{Conclusions}

The beneficial clinical effects of FTS reported here support the findings of other groups and our data on perioperative immunity suggest that better-preserved cellular and humoral immunity may contribute to the improvement of postoperative results in fast-track patients. The precise mechanism of changes in immunological parameters in FTS needs further study.

\section{Abbreviations}

ASA, American Society of Anesthesiologists; BMI, body mass index; CRP, Creactive protein; $E N$, enteral nutrition; ERAS, enhanced recovery after surgery; FTS, fast-track surgery; IgA, immunoglobulin A; IgG, immunoglobulin G; IgM, immunoglobulin M; IL-6, interleukin-6; PCA, patient-controlled analgesia; POD, postoperative days

\section{Acknowledgments}

The authors would like to acknowledge the assistance of Dr. Shouqian Cao and Guibin Zhao for their assistance in establishing the FTS surgery protocol.

\section{Funding}

This work did not receive funding.

\section{Availability of data and materials}

The raw data will not be shared, because a related article that we are writing is not completed. We will add more data on the basis of these data to explore new theory in the later article.

\section{Authors' contributions}

$\mathrm{CL}, \mathrm{SL}$ and XS designed the study. LY participated in the design of the study and performed the statistical analysis. CL, SL, LY, WJ, YL, NJ, ZJ and XS were involved in the patients' examination, treatment, observation and serum sample collection, including follow-up. CL, SL and XS participated in writing the manuscript. All authors read and approved the final manuscript.

\section{Consent for publication \\ Not applicable.}

Ethics approval and consent to participate

All work performed in this study was carried out in accordance with the Declaration of Helsinki. The study was approved by the Research Ethics Committee of Harbin Medical University, and written informed consent was obtained from all subjects.

\section{Author details}

'Department of Thoracic Surgery, Harbin Medical University Cancer Hospital, Harbin, Heilongjiang Province, China. ${ }^{2}$ Department of Thoracic Surgery, The Fourth Affiliated Hospital of Harbin Medical University, Harbin, Heilongjiang Province, China. ${ }^{3}$ Department of Thoracic Surgery, Hainan Cancer Hospital, Haikou, Hainan Province, China.

Received: 16 May 2015 Accepted: 5 July 2016

Published online: 11 July 2016

\section{References}

1. Wichmann MW, Eben R, Angele MK, Brandenburg F, Goetz AE, Jauch KW. Fasttrack rehabilitation in elective colorectal surgery patients: a prospective clinical and immunological single-centre study. ANZ J Surg. 2007;77(7):502-7.

2. Cao S, Zhao G, Cui J, Dong Q, Qi S, Xin Y, Shen B, Guo Q. Fast-track rehabilitation program and conventional care after esophagectomy: a retrospective controlled cohort study. Support Care Cancer. 2013;21(3):707-14.

3. Zhao G, Cao S, Cui J. Fast-track surgery improves postoperative clinical recovery and reduces postoperative insulin resistance after esophagectomy for esophageal cancer. Support Care Cancer. 2014;22(2):351-8.

4. Cerfolio RJ, Bryant AS, Bass CS, Alexander JR, Bartolucci AA. Fast tracking after Ivor Lewis esophagogastrectomy. Chest. 2004;126(4):1187-94.

5. Cuthbertson D, Tilstone WJ. Metabolism during the postinjury period. Adv Clin Chem. 1969:12:1-55.

6. Kehlet $\mathrm{H}$, Wilmore DW. Evidence-based surgical care and the evolution of fast-track surgery. Ann Surg. 2008;248(2):189-98.

7. Cuesta MA, Biere SS, Henegouwen MI, van der Peet DL. Randomised trial, Minimally Invasive Oesophagectomy versus open oesophagectomy for patients with resectable oesophageal cancer. J Thorac Dis. 2012;4(5):462-4.

8. Kehlet $\mathrm{H}$, Wilmore DW. Multimodal strategies to improve surgical outcome. Am J Surg. 2002;183(6):630-41.

9. Nygren J, Soop M, Thorell A, Sree Nair K, Ljungqvist O. Preoperative oral carbohydrates and postoperative insulin resistance. Clin Nutr. 1999; 18(2):117-20

10. Wagner IJ, Rombeau JL. Nutritional support of surgical patients with inflammatory bowel disease. Surg Clin North Am. 2011;91(4):787-803. viii.

11. Ding $D$, Feng $Y$, Song B, Gao $S$, Zhao J. Effects of preoperative and postoperative enteral nutrition on postoperative nutritional status and immune function of gastric cancer patients. Turk J Gastroenterol. 2015; 26(2):181-5.

12. Beier-Holgersen R, Brandstrup B. Influence of postoperative enteral nutrition on cellular immunity. A random double-blinded placebo controlled clinical trial. Int J Colorectal Dis. 2012;27(4):513-20. 
13. Watkins LR, Maier SF, Goehler LE. Immune activation: the role of proinflammatory cytokines in inflammation, illness responses and pathological pain states. Pain. 1995;63(3):289-302.

14. Volk T, Schenk M, Voigt K, Tohtz S, Putzier M, Kox WJ. Postoperative epidural anesthesia preserves lymphocyte, but not monocyte, immune function after major spine surgery. Anesth Analg. 2004;98(4):1086-92. table of contents.

15. Moore CM, Desborough JP, Powell H, Burrin JM, Hall GM. Effects of extradural anaesthesia on interleukin- 6 and acute phase response to surgery. Br J Anaesth. 1994;72(3):272-9.

16. Beilin B, Shavit Y, Trabekin E, Mordashev B, Mayburd E, Zeidel A, Bessler H. The effects of postoperative pain management on immune response to surgery. Anesth Analg. 2003;97(3):822-7.

17. Fares KM, Mohamed SA, Hamza HM, Sayed DM, Hetta DF. Effect of thoracic epidural analgesia on pro-inflammatory cytokines in patients subjected to protective lung ventilation during Ivor Lewis esophagectomy. Pain Physician. 2014;17(4):305-15.

18. Dresner SM, Lamb PJ, Shenfine J, Hayes N, Griffin SM. Prognostic significance of peri-operative blood transfusion following radical resection for oesophageal carcinoma. Eur J Surg Oncol. 2000;26(5):492-7.

19. Luban NL, Kelleher Jr JF, Reaman GH. Altered distribution of T-lymphocyte subpopulations in children and adolescents with haemophilia. Lancet. 1983; 1(8323):503-5.

20. Waymack JP, Gallon L, Barcelli U, Trocki O, Alexander JW. Effect of blood transfusions on immune function. III. Alterations in macrophage arachidonic acid metabolism. Arch Surg. 1987;122(1):56-60.

21. Langley SM, Alexiou C, Bailey DH, Weeden DF. The influence of perioperative blood transfusion on survival after esophageal resection for carcinoma. Ann Thorac Surg. 2002;73(6):1704-9.

22. Cruickshank AM, Fraser WD, Burns HJ, Van Damme J, Shenkin A. Response of serum interleukin-6 in patients undergoing elective surgery of varying severity. Clin Sci (Lond). 1990;79(2):161-5.

23. Yoshimura A, Wakabayashi Y, Mori T. Cellular and molecular basis for the regulation of inflammation by TGF-beta. J Biochem. 2010;147(6):781-92.

24. Sammour T, Kahokehr A, Chan S, Booth RJ, Hill AG. The humoral response after laparoscopic versus open colorectal surgery: a meta-analysis. J Surg Res. 2010;164(1):28-37.

25. Basse L, Jakobsen DH, Bardram L, Billesbolle P, Lund C, Mogensen T, Rosenberg J, Kehlet $\mathrm{H}$. Functional recovery after open versus laparoscopic colonic resection: a randomized, blinded study. Ann Surg. 2005;241(3):416-23.

\section{Submit your next manuscript to BioMed Central and we will help you at every step:}

- We accept pre-submission inquiries

- Our selector tool helps you to find the most relevant journal

- We provide round the clock customer support

- Convenient online submission

- Thorough peer review

- Inclusion in PubMed and all major indexing services

- Maximum visibility for your research

Submit your manuscript at www.biomedcentral.com/submit

) Biomed Central 